\title{
MAPEANDO A ESCRITA DE ESTUDANTES DO \\ ENSINO FUNDAMENTAL: EM FOCO \\ O ARTIGO DE OPINIÃO
}

\section{MAPPING THE STUDENTS WRITING OF FUNDAMENTAL EDUCATION STUDENTS: IN FOCUS THE ARTICLE OF OPINION}

\author{
Cleiton Reisdörfer Silva* \\ Francieli Matzenbacher Pinton ${ }^{* *}$
}

\section{RESUMO}

Neste trabalho, buscamos analisar as características linguístico-discursivas recorrentes em artigos de opinião produzidos por estudantes da educação básica. Como aporte teórico para análise do corpus, partimos da noção de gênero da Sociorretórica (MILLLER, 1984, 2014; BAZERMAN, 2011a; 2011b; 2015), de princípios teórico-metodológicos de Swales (1990) e de conceitos da Gramática Sistêmico-Funcional (GSF) (HALLYDAY; MATTHIESSEN, 2014). O corpus de pesquisa é constituído de 59 artigos de opinião produzidos por alunos do $9^{\circ}$ do Ensino Fundamental em contexto de sala de aula. Os resultados da análise indicam que a estrutura retórica do artigo de opinião produzido por esses alunos apresenta movimentos e passos característicos da situação comunicativa de produção dos textos. Verificamos que os artigos de opinião escritos pelos alunos apresentam os seguintes movimentos: 1 - Contextualização; 2 - Apresentação da tese; 3 - Defesa da tese; 4 Síntese e reiteração. Quantificando os dados, verificamos que os alunos utilizam com maior frequência os Movimentos 2 e 3. A análise dos significados ideacionais demonstrou que os alunos utilizam processos materiais associados a participantes nomes genéricos para indicar fatos e ações; identificam e atribuem características ao campo do texto, a um objeto semiótico ou a uma abstração semiótica por meio de processos relacionais; e se posicionam utilizando participantes pronomes pessoais associados a processos relacionais/mentais. A análise dos recursos interpessoais indicou que, dentre esses recursos, os alunos utilizam predominantemente verbos e expressões modais e adjuntos de comentário. Os achados podem fomentar a produção de materiais didáticos que privilegiem atividades didáticas que auxiliem os jovens escritores em sua prática de escrita de maneira situada.

Palavras-chave: artigo de opinião; estrutura retórica;recursos linguísticos.

\footnotetext{
* Universidade Federal de Santa Maria, UFSM, Santa Maria, RS, Brasil. cleitonreisdorfer08@gmail.com. Orcid: https://orcid.org/0000-0003-4813-7308

** Universidade Federal de Santa Maria, UFSM, Santa Maria, RS, Brasil. francieli.matzembacher@ gmail.com.

Orcid: https://orcid.org/0000-0001-6821-4927
} 


\begin{abstract}
In this work, we seek to analyze the recurrent linguistic-discursive characteristics in opinion articles produced by basic education students. As a theoretical contribution to the analysis of the corpus, we start from the notion of Socio-rhetorical genre (MILLLER, 1984, 2014; BAZERMAN, 2011a; 2011b; 2015), from Swales (1990) theoretical-methodological principles and from the concepts of Systemic-Functional Grammar (SFG) (HALLYDAY; MATTHIESSEN, 2014). The research corpus is made up of 59 opinion articles produced by students of the 9th grade of Elementary School in the classroom context. The results of the analysis indicate that the rhetorical structure of the opinion article produced by these students presents typical movements and steps of the communicative situation of production of the texts. We verified that the articles of opinion written by the students present the following movements: 1 - Contextualization; 2 - Thesis presentation; 3 Thesis defense, 4 - Synthesis and reiteration. Quantifying the data, we found that students use Movements 2 and 3 more frequently. The analysis of ideational meanings has shown that students use material processes associated with generic names participants to indicate facts and actions, identify and attribute characteristics to text field, semiotic object or semiotic abstraction through relational processes, and position themselves using personal pronouns participants associated with relational processes. The analysis of interpersonal resources indicated that, among these resources, students predominantly use modal verbs and expressions and comment adjuncts. The findings can foster the production of didactic materials that emphasize didactic activities that assist young writers in their writing practice in a situated way.
\end{abstract}

Keywords: opinion article; rhetorical structure; linguistics resources.

\title{
INTRODUÇÃO
}

A escrita é uma importante forma de ação social que possibilita aos indivíduos a participação em práticas discursivas variadas, desde a produção de mensagens em redes sociais até a realização de atividades mais complexas como a escrita de um artigo acadêmico para um periódico especializado. A partir disso, segundo Bazerman (2015), em uma sociedade burocratizada como a atual, apropriar-se socialmente da escrita pode ser a diferença entre obter sucesso profissional ou não, já que diferentes níveis de habilidade de escrita são requeridos de acordo com cada situação comunicativa. Os gêneros emolduram e situam o momento da escrita, e a escrita, portanto, realiza ações nos moldes definidos pelo gênero (BAZERMAN, 2015). Apesar disso o gênero não define exatamente como as ações vão acontecer, somente fornece orientações, compreensões, instrumentos e trajetórias possíveis.

Considerando a escrita como essencialmente dialógica, interativa e social, e também como um meio para que mudemos as circunstâncias de nosso entorno social, dois aspectos são fundamentais: i) entender a escrita como parte das condições sociais e da capacidade humana e ii) recriar a circunstância social da comunicação na escrita. Assim, para desenvolvermos uma retórica da escrita, 
primeiramente, devemos compreender "como a escrita comunica a distância, como cria contextos de interação e como pode falar aos contextos que evoca e de que participa" (BAZERMAN, 2015, p. 21). Em segundo lugar, devemos compreender que, como toda atividade humana, a retórica segue a lógica da estrutura da ação humana, ou seja, toda ação é realizada para que os indivíduos possam sair de uma condição anterior menos favorável para uma condição posterior mais favorável (MISES, 2010), ou seja, falamos e escrevemos buscando atingir objetivos, construir relações, ainda que todas essas ações e intenções não sejam explícitas.

Partindo desses pressupostos, entendemos que a compreensão de como, por que e para que os alunos escrevem em uma determinada situação comunicativa pode ser chave para o desenvolvimento de atividades didáticas que privilegiem um contexto situado de ensino de escrita e favoreçam o aprendizado dessa atividade. Diversos trabalhos, assim como este, têm investigado a produção de textos em contexto escolar, evidenciando a preocupação em torno desse assunto. Dentre esses trabalhos, destacamos a tese de Ribeiro (2012), que analisou, em textos de alunos do ensino fundamental e do ensino médio, as estratégias argumentativas utilizadas tendo como base as categorias argumentativas (PERELMAN; OLBRECHTS-TYTECA, 2014). De forma similar, a tese de Santos (2015), que investigou a organização da argumentação em textos produzidos por alunos do Ensino Médio a fim de identificar os níveis de estruturação argumentativa nesses textos. Ferreira (2018), em trabalho de dissertação de Mestrado, analisou as estratégias argumentativas na produção escrita de artigos de opinião no Ensino Fundamental, buscando identificar como se dá a construção da argumentação. Por fim, sinalizamos o trabalho de Barros (2016), que investigou a construção da contra-argumentação mediada por operadores de conformidade e contraposição em artigos de opinião produzidos por alunos do ensino fundamental.

Dessa forma, buscando ampliar os estudos já desenvolvidos e contribuir para um ensino explícito de linguagem voltado às necessidades de estudantes da educação básica, este trabalho tem como objetivo analisar exemplares de artigos de opinião produzidos em contexto escolar em termos de estrutura retórica e de recorrências léxico-gramaticais.

Para efetivar esse objetivo, este artigo está organizado em cinco seções, além desta Introdução. Na seção de Revisão da literatura, apresentamos o aporte teórico desta pesquisa, destacando a noção de gênero na perspectiva da Sociorretórica (BAZERMAN, 2011a; 2011b; 2015; MILLER, 1994) e o Sistema de Transitividade 
e de $\mathrm{MODO}^{1}$ da Gramática Sistêmico-Funcional (HALLYDAY; MATTHIESSEN, 2014). Na seção de metodologia, descrevemos a abordagem da pesquisa, o contexto de geração dos dados, a constituição do corpus e os procedimentos de análise. Por fim, descrevemos e analisamos o gênero artigo de opinião em termos de estrutura retórica e marcas linguísticas.

\section{REVISÃO DA LITERATURA}

Considerando que os gêneros do discurso nos são dados "quase da mesma forma que nos é dada a língua materna" (BAKHTIN, 2011, p. 283), podemos afirmar que aprendemos a moldar o nosso discurso em formas de gênero enquanto aprendemos a interagir por meio da linguagem. Para Bakhtin (2011), quando ouvimos o discurso alheio, identificamos o seu gênero pelas primeiras palavras, percebemos "um determinado volume, uma determinada construção composicional, prevemos o fim, isto é, desde o início temos a sensação do conjunto do discurso" (BAKHTIN, 2011, p. 283).

Esses índices que a linguagem fornece podem ser analisados a partir de marcas típicas de cada situação. Bakhtin, reconhecendo essas possibilidades analíticas, toma o enunciado particular e único como unidade de comunicação discursiva para análise, tendo em vista que "cada esfera de utilização da língua elabora seus tipos relativamente estáveis de enunciados" (BAKHTIN, 2011, p. 279) e a identificação, a categorização e a possibilidade de aprendizado desses enunciados faz com que possamos denominar uma coleção de textos como integrantes de um determinado gênero do discurso. Assim, de acordo o autor (2011, p. 262), "os gêneros são tipos relativamente estáveis de enunciados" com conteúdo temático, estrutura composicional e estilo, características essas que são reconhecíveis em cada cultura.

$\mathrm{Na}$ perspectiva da Sociorretórica, os teóricos definem gênero como uma ação social e retórica, tipificada e recorrente (MILLER, 1994; BAZERMAN, 2011 a ; 2015). Para esses autores, o foco está na interação social e na construção de sentidos que ocorre nessa interação. Além disso, para Bazerman (2011a) e Miller (1994), o conceito de tipificação é relevante para expressar a ideia de que as pessoas recorrem a formas textuais familiares para se comunicarem. Essas formas familiares organizam a vida das pessoas na sociedade, permitindo que realizem atividades de diversos níveis de complexidade e criem "novas realidades de significação, relações

1. São três as utilizações da palavra modo na tradução para o Português: i) $M O D O$ - o nome do sistema; ii) modo - a variável do registro; iii) Modo - o componente da oração, junto com o resíduo, no Sistema de MODO. 
e conhecimento, fazendo uso de textos" (BAZERMAN, 2011a, p. 19). Essa definição, muito utilizada na literatura dos estudos linguísticos, é bastante eficaz para a compreensão do modo como a sociedade é organizada. Para o autor,

[...] gêneros não são apenas formas. Gêneros são formas de vida, modos de ser. São frames para a ação social. São ambientes para a aprendizagem. São os lugares onde o sentido é construído. Os gêneros moldam os pensamentos que formamos e as comunicações através das quais interagimos. Gêneros são os lugares familiares uns com os outros e são os modelos que utilizamos para explorar o não-familiar. (BAZERMAN, 2011b, p. 23).

Esse potencial encapsulado no gênero faz dele um recurso rico e multidimensional que auxilia a situar nossa atividade discursiva em meio a situações altamente estruturadas e uma complexa rede de dinâmicas sociais e psicológicas das quais os gêneros são a "realização visível" (BAZERMAN, 2011b, p 24; 2015, p. 48). Compreender esses recursos, atividades e processos é a condição para que nossos enunciados sejam eficazes.

Nesse sentido, a descrição retórica do gênero poderá fornecer indicações sobre como utilizá-lo em determinadas situações. Em razão disso, entendemos que o mapeamento da escrita de artigos de opinião produzidos por estudantes do ensino fundamental pode auxiliar efetivamente na construção de atividades e tarefas pedagógicas que possibilitem agir em situações específicas de uso da linguagem escrita, por exemplo, defender um ponto de vista diante de uma questão polêmica.

As ações em situações específicas por meio da escrita, foco desta pesquisa, são realizadas em moldes definidos pelos gêneros. Esses moldes podem ser considerados tanto em configurações contextuais e situacionais quanto em configurações textuais e retóricas. Assim, compreendendo que parte da definição de gêneros é a noção de que esses apresentam ações retóricas reconhecíveis e recorrentes, adotamos princípios teórico-metodológicos propostos por Swales (1990). O pesquisador propõe que a análise de gêneros focalize a estrutura retórica dos textos em termos de movimentos e passos e que essa organização textual revelará aspectos da situação comunicativa à qual o texto está ligado. Para Swales (1990), o movimento retórico é uma unidade discursiva que desempenha uma função comunicativa e os passos são unidades menores que se combinam para formar a informação de cada movimento.

Assim, analisar os artigos de opinião com base nesses princípios teóricometodológicos possibilitará a identificação do modo como os alunos organizam os movimentos retóricos nos exemplares de artigos de opinião, explicitando aspectos da situação de comunicação em que foram produzidos. Além disso, a análise dos movimentos e passos nos textos poderá comprovar a existência de regularidades que configurariam especificidades do contexto de produção dos textos, aproximando 
ou distanciando esses textos de outros produzidos em contextos distintos, como a esfera midiática, por exemplo.

\subsection{Artigo de opinião: definição e funcionalidade}

$\mathrm{O}$ artigo de opinião é vinculado à esfera jornalística e está presente em veículos como jornais, revistas e periódicos, em suas versões online ou impressa. Em geral, jornais e revistas possuem seções específicas para a publicação de artigos de seus colunistas e de eventuais colaboradores, tidos como formadores de opinião ou referências em suas áreas de atuação, geralmente. Nesses espaços, os produtores dos textos mobilizam as estratégias argumentativas e a estrutura do gênero de modo a impactar de forma positiva sua audiência. As respostas a esses textos geralmente ocorrem por meio de cartas de leitores, textos também argumentativos. Nesse sentido, para Gagliardi e Amaral (2004, p. 06), a produção de um artigo de opinião pressupõe uma situação social em que estão envolvidos um meio de comunicação, um produtor que emitirá sua opinião e leitores interessados em conhecer a opinião do articulista sobre o assunto em questão.

Desse modo, a relevância do artigo de opinião advém de abordar questões sociais, políticas e culturais de interesse em determinado contexto, local ou amplo, possibilitando o diálogo de ideias e de temas presentes nesse contexto. Em relação ao alcance do gênero, o artigo de opinião apresenta um determinado ponto de vista referindo-se a problemáticas situadas no nível das pessoas e dos grupos, enquanto o editorial, também um texto argumentativo, centra-se no nível das instituições. Bräkling (2000) defende que é condição indispensável para a produção de um artigo de opinião a existência de uma questão controversa a ser debatida em determinado contexto, uma questão que gere polêmica em determinados círculos sociais. Desse modo, o artigo de opinião apresenta alta carga avaliativa em relação aos pontos de vista defendidos ou criticados e em relação às questões debatidas. Além da tese, marcada de forma avaliativa, as vozes inseridas são também alvo de avaliação, aceitação ou refutação, buscando atender à necessidade de defender um ponto de vista $x$ ou $y$.

Oliveira (2004), em seu estudo, analisa a organização retórica de artigos de opinião produzidos em contexto escolar e apresenta a padronização dos seguintes movimentos e passos: 


\title{
Quadro 1. Organização retórica do artigo de opinião
}

\author{
Unidade retórica 1 - Apresentação do tema \\ Subunidade $1 \mathrm{~A}$ - Apresentando o fato jornalístico e / ou \\ Subunidade $1 \mathrm{~B}$ - Apresentando o(s) antecedente(s) do tema em questão \\ Unidade retórica 2 - Apresentação de uma tomada de posição \\ Subunidade 1 - Formulando uma tese e / ou \\ Subunidade 2 - Apresentando diferente(s) argumento(s) que justificam a tese \\ Unidade retórica 3 - Avaliação \\ Subunidade 1A - Apresentando processo(s) estimativo(s) de juízo(s) de valor(es) e / ou \\ Subunidade 1B - Apresentando causa(s) e consequência(s) \\ Unidade retórica 4 - Conclusão \\ Subunidade 1A - Apresentando conclusão(ões) e / ou \\ Subunidade $1 \mathrm{~B}$ - Indicando perspectiva(s)
}

Fonte: (OLIVEIRA, 2004, p. 73).

De forma similar, Freitas (2009) propõe a estrutura retórica do artigo de opinião após analisar nove exemplares de artigo de opinião do caderno didático das Olimpíadas de Língua Portuguesa. Os artigos presentes nesse caderno foram utilizados para auxiliar no aprendizado dos alunos, com isso supõe-se que tenham sido selecionados por representarem um determinado "padrão" para o gênero. Os movimentos são caracterizados da seguinte forma:

a) Movimento (I): identificar o título e autoria - informa o título e o articulista.

$\beta$ ) Movimento (II): apresentar uma questão polêmica - introduz questões controversas e polêmicas de relevância social e sintoniza o leitor dentro da questão a ser abordada no artigo.

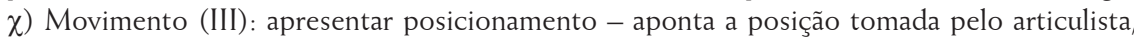
defendendo-a, utilizando argumentos consistentes e bem fundamentados, apresentando convicção na tomada de posição.

ठ) Movimento (IV): apresentar os argumentos - contextualiza a questão abordada no texto, explicitando mediante a apresentação de argumentos (prova, indício) e dialoga com diferentes pontos de vista que circulam sobre a polêmica.

ع) Movimento (V): apresentar a conclusão - apresenta uma avaliação, encerramento, por parte do articulista, de forma positiva ou negativa, apresentando considerações finais, previsão de futuro em relação aos fatos relatados ou em relação aos argumentos que norteiam a interpretação exposta, podendo oferecer uma solução.

$\phi)$ Movimento (VI): apresentar dados de identificação do autor - expõe elementos que podem levar o leitor a um contato extra com o articulista. (FREITAS, 2009, p. 62-67).

Entendemos que a descrição da estrutura retórica do artigo de opinião pode revelar as características linguístico-discursivas da escrita de estudantes do Ensino Fundamental, considerando o contexto situado desta pesquisa. Para analisar o artigo de opinião, observamos a estrutura retórica e os elementos linguísticos que 
o constituem. Esses elementos podem ser identificados com o auxílio da Gramática Sistêmico-Funcional, a qual abordamos na próxima seção.

\subsection{Gramática Sistêmico-Funcional}

A Gramática Sistêmico-Funcional (GSF) é uma teoria de descrição gramatical da linguagem em uso (HALLIDAY, MATTHIESSEN, 2014). A GSF, associada à Linguística Sistêmico-Funcional, que, por sua vez, é "uma teoria geral do funcionamento da linguagem humana, concebida a partir de uma abordagem descritiva baseada no uso linguístico" (GOUVEIA, 2009, p. 14), fornecendo assim um extenso aparato teórico-analítico para compreensão dos textos produzidos na sociedade.

A GSF adota a oração como objeto de análise por ser essa a unidade de processamento da léxico-gramática, a instância em que se realizam simultaneamente os três significados possíveis produzidos em contexto: "uma representação significado como conteúdo; uma troca - significado como forma de ação; e uma mensagem - significado como relevância para o contexto" (CUNHA; SOUZA, 2011, p. 28). Diante disso, para buscarmos compreender os significados expressos gramaticalmente, é possível tomar um, ou mais, dos sistemas para análise da oração descritos a seguir - Transitividade, relacionado à metafunção ideacional; MODO, relacionado à metafunção interpessoal ${ }_{i}$ Estrutura temática, relacionada à metafunção textual.

Halliday $(1985 ; 1993)$ observou que a comunicação humana é um processo semiótico e que uma forma semiótica humana prototípica é o uso da linguagem. Nesse sentido, a linguagem é compreendida como um recurso para construir significados socialmente (HALLIDAY; MATTHIESSEN, 2014), para agir sobre o mundo e sobre as pessoas. Por essas razões, linguagem, texto e contexto organizam a experiência humana e o Sistema de Transitividade é a categoria gramatical responsável pela representação dessa experiência, a qual pode ser compreendida como um fluxo de eventos ou acontecimentos ligados a "agir, dizer, sentir, ser e ter" (CUNHA; SOUZA, 2011, p. 67), categorizados pela Transitividade como diferentes processos que modelam uma parte da realidade.

O Sistema de Transitividade descreve a oração, em termos de participantes, processos e circunstâncias. Os participantes estão categorizados em conscientes seres humanos, e não conscientes - materiais e semioses, de acordo com Halliday e Matthiessen (2014, p. 215). Os participantes materiais podem ser animais, objetos, substâncias ou abstrações materiais. Os participantes semioses podem ser instituições, objetos semióticos ou abstrações semióticas. 
Os processos representam aspectos do mundo físico, mental e social (FUZER , CABRAL, 2014, p. 41) e, de acordo com cada representação, podemos identificar o tipo de processo utilizado. Os três principais tipos de processos são: materiais - fazer, acontecer; mentais - sentir, pensar; e relacionais - ter. Entre eles localizam-se os processos: verbais - dizer; comportamentais - comportar-se; existenciais - existir.

Na GSF, o tipo de oração está atrelado ao tipo de processo utilizado, pois a este estão relacionados diferentes tipos de participantes, que serão, assim como as circunstâncias, afetados pelo processo. O Quadro 2 apresenta os tipos de processos, os significados comumente associados a cada processo e os participantes.

Quadro 2. Tipos de processos

\begin{tabular}{|c|c|c|c|}
\hline PROCESSOS & SIGNIFICADOS & PARTICIPANTES & Exemplo \\
\hline $\begin{array}{l}\text { Materiais } \\
\text { Transformativo } \\
\text { Criativo }\end{array}$ & Fazer e acontecer & $\begin{array}{l}\text { Ator } \\
\text { Meta } \\
\text { Escopo } \\
\text { Beneficiário (recebedor, } \\
\text { cliente) } \\
\text { Atributo }\end{array}$ & Comprar, vender, mexer, \\
\hline $\begin{array}{l}\text { Mentais } \\
\text { Perceptivo } \\
\text { Cognitivo } \\
\text { Emotivo } \\
\text { Desiderativo }\end{array}$ & $\begin{array}{l}\text { Sentir, perceber, } \\
\text { pensar e desejar }\end{array}$ & $\begin{array}{l}\text { Experienciador e } \\
\text { Fenômeno }\end{array}$ & Perceber, ver, ouvir, \\
\hline $\begin{array}{l}\text { Relacionais } \\
\text { Intensivo } \\
\text { Possessivo } \\
\text { Circunstancial }\end{array}$ & $\begin{array}{l}\text { relação entre } \\
\text { duas entidades: } \\
\text { caracterização ou } \\
\text { identificação. }\end{array}$ & $\begin{array}{l}\text { Identificado } \\
\text { Identificador }\end{array}$ & Ser, estar, ter \\
\hline $\begin{array}{l}\text { Verbais } \\
\text { Atividade } \\
\text { Semiose }\end{array}$ & Dizer & $\begin{array}{l}\text { Dizente } \\
\text { Verbiagem } \\
\text { Receptor } \\
\text { Alvo }\end{array}$ & Dizer, perguntar, afirmar \\
\hline Existenciais & Existir & Existente & Haver, existir \\
\hline Comportamentais & Comportar-se & $\begin{array}{l}\text { Comportante } \\
\text { Comportamento }\end{array}$ & Rir, chorar, dormir \\
\hline
\end{tabular}

Fonte: (FUZER; CABRAL 2014, p. 81-82).

Além disso, no Sistema de Transitividade, é possível identificar as circunstâncias. Ainda que sejam indicadas como opcionais, as circunstâncias são indicadores importantes do contexto no qual se desenvolve a ação desempenhada 
pelo processo, são elementos situadores que indicam em quais condições os eventos foram desenvolvidos e qual parte da realidade estão descrevendo.

Quadro 3. Tipos de circunstâncias

\begin{tabular}{|l|l|}
\hline \multirow{4}{*}{ CIRCUNSTÂNCIAS } & Distância (A que distância?) \\
\cline { 2 - 2 } & Duração (Há quanto tempo?) \\
\cline { 2 - 2 } & Frequência (Quantas vezes?) \\
\hline \multirow{4}{*}{ Localização } & Lugar (Onde?) \\
\cline { 2 - 2 } & Tempo (Quando?) \\
\hline \multirow{4}{*}{ Modo 2} & Meio (Como? Com o quê?) \\
\cline { 2 - 2 } & Qualidade (Como?) \\
\cline { 2 - 2 } & Comparação (Como é? Com que parece? \\
\cline { 2 - 2 } & Grau (Quanto?) \\
\hline \multirow{4}{*}{ Causa } & Razão (Por quê?) \\
\cline { 2 - 2 } & Finalidade (Para quê?) \\
\cline { 2 - 2 } & Benefício/Representação (Por quem?) \\
\hline Contingência & Condição (Por quê?) \\
\hline \multirow{2}{*}{ Acompanhamento } & Falta/Omissão \\
\cline { 2 - 2 } & Concessão \\
\hline \multirow{2}{*}{ Papel } & Companhia (Com quê? Com o quê?) \\
\cline { 2 - 2 } & Adição (Quem mais? O que mais?) \\
\hline Assunto & (Sobre o quê?) \\
\hline \multirow{2}{*}{ Ângulo } & Fonte \\
\cline { 2 - 2 } & Ponto de vista \\
\hline
\end{tabular}

Fonte: Elaborado por Fuzer e Cabral (2014, pp. 53-54), baseado em Halliday e Matthiessen (2004, pp. 26-263).

Em nossa análise, buscaremos também observar o Sistema de MODO. O Sistema de MODO é o recurso utilizado para expressar a interação entre os participantes de uma situação comunicativa. Esse sistema é, portanto, um recurso interpessoal que auxilia no estabelecimento e manutenção das relações sociais no texto (HALLIDAY; MATTHIESSEN, 2014).

Os componentes básicos da oração no Sistema de MODO são o Modo e o Resíduo. Os elementos do Modo são o Sujeito e o Finito. O primeiro são os

2. A circunstância de modo é um dos elementos constituintes da figura na oração. 
grupos nominais ou pronomes utilizados para reiterar quem são os participantes de uma situação - o sujeito da oração. O segundo é parte do grupo verbal e auxilia a demarcar o tempo, a polaridade e a modalidade (HALLIDAY; MATTHIESSEN, 2014, p.146).

Neste trabalho, exploramos especificamente a modalidade, que é um elemento importante do Sistema de MODO. A modalidade é, de acordo com Halliday e Matthiessen (2014), um recurso interpessoal que expressa significados relacionados aos julgamentos dos falantes em diferentes graus por meio de verbos modais, adjuntos modais e grupos adverbiais. Modalizar significa assumir uma posição, expressar uma opinião ou julgar o tema em questão. Esse recurso auxilia o estabelecimento de relações indicadoras do comprometimento do escritor com o que diz e com as vozes trazidas para o seu texto (MARTIN; WHITE, 2005).

Além disso, a modalidade tem relação com as quatro funções básicas da fala - oferta, comando, declaração e pergunta. Ao trocarmos informações por meio de proposições, declarando ou perguntando, utilizamos modalidade epistêmica, também chamada de modulação. Ao trocarmos bens e serviços por meio de propostas - ofertas ou comandos - utilizamos modalidade deôntica, chamada de modulação. Modalidade e polaridade auxiliam a situar os enunciados em níveis intermediários entre os polos positivo e negativo, construindo a região de incerteza que existe entre "sim" e "não" (HALLIDAY; MATTHIESSEN, 2014).

A modalização refere-se às proposições em termos de probabilidade ou usualidade - modalidade epistêmica. Já a modulação refere-se às propostas estabelecendo níveis de obrigação ou níveis de inclinação - modalidade deôntica. Quanto à orientação, a modalidade poderá ser subjetiva/objetiva e explícita/implícita, conforme a fonte da convicção. Quanto ao valor, poderá ser baixo, médio e alto. Quanto à polaridade, positiva ou negativa (HALLIDAY, MATTHIESSEN, 2014).

Por fim, a partir da noção de gênero como ação social e a partir das categorias da GSF apresentaremos como são construídas a experiência e as relações nos artigos de opinião do corpus. A análise dos processos indicará como os eventos são representados nos textos e como são construídos os sentidos em termos das ações realizadas. A análise do sistema de $\mathrm{MODO}$, por sua vez, fornecerá indícios sobre a carga valorativa interpessoal expressa nos textos.

\section{PERCURSO METODOLÓGICO}

O universo de análise deste trabalho é constituído de artigos de opinião produzidos por alunos do $9^{\circ}$ ano do ensino fundamental de uma escola da rede pública 
municipal de Santa Maria, RS. O projeto de pesquisa foi apresentado e aprovado pelo Comitê de Ética em Pesquisa, conforme o Certificado de Apresentação para Apreciação Ética (CAAE: 75215017.8.0000.5346).

O corpus compreende 59 artigos de opinião resultantes de sequências de atividades didáticas desenvolvidas por professores em formação durante as oficinas de leitura e produção textual ofertadas pelos projetos de extensão "Produção e avaliação de textos no contexto escolar" (2015) e "Práticas de letramento no contexto escolar" (2016 e 2017) e compõem um banco de dados. Os exemplos retirados do corpus foram identificados com uma legenda organizada de acordo com identificação numérica do produtor, o ano da produção e o tema do texto (Escola Sem Partido, Redução da Maioridade Penal, Reforma do Ensino Médio, Livros digitais). Assim, \#11.16.ESP significa: aluno número 11, ano de 2016, tema Escola Sem Partido. Os exemplos preservam a escrita dos estudantes, mantendo eventuais inadequações na escrita.

Os procedimentos de análise do corpus compreenderam três etapas: i) descrição da organização retórica dos artigos de opinião em termos de movimentos e passos; ii) identificação das recorrências léxico-gramaticais presentes nos movimentos e passos; iii) verificação das recorrências léxico-gramaticais e de sua relação com a situação discursiva. Para realização da etapa um, inicialmente identificamos parcelas semânticas e lexemas ricos em significação que desempenham determinada função discursiva nos textos. Na etapa dois, isolamos as orações do corpus para identificar os tipos de processos e os tipos de participantes nas orações, conforme o Quadro 5 - Participantes nas orações. Após isso, identificamos os recursos interpessoais utilizados. $\mathrm{Na}$ etapa três, relacionamos os achados dos textos com os significados possíveis.

\section{ANÁLISE E DISCUSSÃO DOS RESULTADOS}

A estrutura retórica é composta por movimentos e passos, os quais são unidades discursivas que desempenham funções comunicativas específicas. Desse modo, entendemos que as regularidades nos movimentos e passos dos textos analisados configuram especificidades do contexto de produção. O quadro a seguir apresenta os movimentos e passos identificados nos textos dos alunos. 
Quadro 4. Movimentos e passos dos artigos de opinião produzidos pelos alunos

\begin{tabular}{|c|c|}
\hline Movimentos & Passos \\
\hline 1. Contextualização & $\begin{array}{l}\text { 1a. Apresentação do tema por meio de definição do problema } \\
\text { e/ou } \\
\text { 1b. Apresentação das posições favoráveis ou contrárias ao tema } \\
\text { e/ou } \\
\text { 1c. Apresentação do tema vinculado a um fato ou evento do cotidiano } \\
\text { e/ou } \\
\text { 1d. Apresentação do tema por meio de uma generalização }\end{array}$ \\
\hline 2. Apresentação da Tese & 2a. Tomada de posição. \\
\hline 3. Defesa da tese & $\begin{array}{l}\text { 3a. Apresentação do primeiro argumento utilizado para defender a tese } \\
\text { e } \\
\text { 3b. Apresentação do segundo argumento utilizado para defender a tese } \\
\text { e } \\
\text { 3c. Apresentação do terceiro argumento utilizado para defender a tese }\end{array}$ \\
\hline 4. Síntese e reiteração & $\begin{array}{l}\text { 4a. Apresentação de medidas ou soluções para o problema debatido } \\
\text { e/ou } \\
\text { 4b. Apresentação de conclusões com base nas premissas dos argumentos }\end{array}$ \\
\hline
\end{tabular}

Fonte: Autores.

Para chegarmos a essa estrutura esquemática, identificamos a ocorrência geral dos movimentos e passos nos textos. Nessa análise, verificamos que, dos 59 textos, 25 apresentam todos os Movimentos retóricos e 34 não apresentam um ou mais Movimentos. O Gráfico 1 apresenta a ocorrência dos Movimentos.

\section{Gráfico 1. Ocorrência dos movimentos}

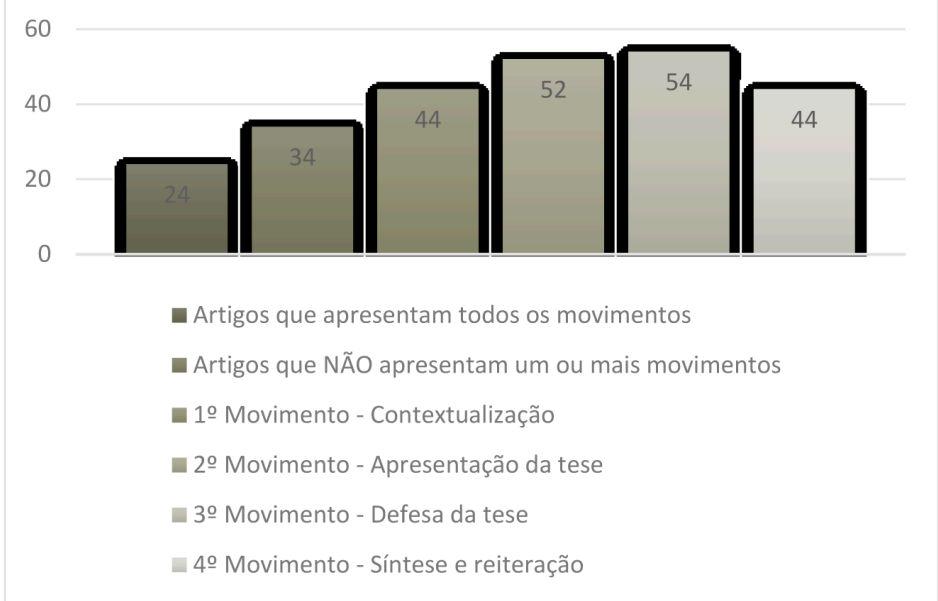

\section{Fonte: Autores.}


Os Movimentos 2 e 3, que explicitam o posicionamento do autor e os argumentos que sustentam esse posicionamento, são os mais recorrentes nos exemplares. Isso parece demonstrar que os alunos participam de práticas discursivas argumentativas como a produção de exemplares do gênero redação escolar e atividades discursivas que demandem atitude responsiva ativa em sala de aula. Isso corrobora o que é afirmado por Bazerman (2011a) e Miller (1994) em termos de tipificação: as pessoas recorrem a formas familiares para se comunicar. Evidentemente, a menor utilização dos Movimentos 1 e 4, da mesma forma, sinaliza que produtores inexperientes de exemplares do gênero artigo de opinião tendem a desconsiderar os Movimentos 1 e 4 por estarem, em alguma medida, mais distantes das práticas discursivas experienciadas em contexto escolar. Essa configuração priorizada nos textos pode sinalizar um processo de escolarização do gênero artigo de opinião, evidenciando marcas desse contexto de ensino e aprendizagem, conforme será apresentado a seguir.

\subsection{Movimento 1 - Contextualização}

No Movimento 1, os alunos apresentam para os leitores o tema que será debatido no texto. Os termos utilizados explicitam o campo semântico em torno desse tema e os participantes, grupos ou pessoas afetadas ou responsáveis pela problemática apresentada no texto. A análise do Movimento de Contextualização evidencia a ocorrência dos Passos a seguir: Passo 1a (Apresentação do tema por meio de definição do problema): 15 ocorrências (Exemplo 1); Passo 1b (Apresentação das posições favoráveis ou contrárias ao tema): 5 ocorrências (Exemplo 2); Passo 1c (Apresentação do tema vinculado a um fato ou evento do cotidiano) : 15 ocorrências (Exemplo 3); Passo 1d (Apresentação do tema por meio de uma generalização): 19 ocorrências (Exemplo 4).

\section{Exemplo 1 - Passo 1a}

Escola sem Partido é uma iniciativa conjunta de estudantes e pais preocupados com o grau de contaminação político-ideológica das escolas brasileiras [...]. \#Art.2.16.ESP.1

\section{Exemplo 2 - Passo $1 \mathrm{~b}$}

A favor da redução da maioridade penal para 16 anos de idade [...].

Sendo contra podemos citar que em nenhum lugar [...]. Art.\#15.16.RMP.

\section{Exemplo 3 - Passo 1c}

Com a crise econômica e lava jato a política tem se tornado um assunto mais frequente nas conversas das pessoas de todas as idades, com isso várias opiniões diferentes tem entrado em conflito, fazendo com que esse assunto chegue à sala de aula. Art.\#7.16.ESP. 


\section{Exemplo 4 - Passo 1d}

1d. É um pouco complicado falar sobre a tal redução da maioridade [...]. Art.\#12.15.RMP.

Além dos passos 1a, 1b e 1c, tipicamente observados em artigos de opinião publicados em jornais, destacamos a identificação do Passo $1 \mathrm{~d}$ como uma estratégia empregada pelos produtores neste contexto específico. Assim, o passo $1 \mathrm{~d}$ parece demarcar o contexto de produção dos artigos de opinião e fornece indícios de que os alunos adaptam o Movimento à sua prática de escrita no contexto escolar.

Em relação às recorrências léxico-gramaticais, o Movimento de Contextualização é marcado pelo frequente emprego de processos relacionais e materiais, participantes do tipo nomes genéricos, abstrações semióticas e campo/ assunto/tema do texto, além de recursos interpessoais como verbos modais, adjuntos de negação e frases interrogativas.

Mapeamos, na Contextualização, um total de 165 orações. Para composição da figura, consideramos a existência de um participante explícito na oração ou elíptico em caso de orações encaixadas ou pronomes pessoais. De acordo com as características semânticas, elaboramos categorias a partir das noções da GSF para facilitar a compreensão do modo como os alunos identificam participantes nas orações, conforme o Quadro 5. Essas categorias servem de base para análise de todos os Movimentos.

Quadro 5. Participantes nas orações

\begin{tabular}{|c|c|c|}
\hline Identificação & Categoria & Exemplo \\
\hline & Nomes genéricos relacionados a seres humanos & muitas pessoas, os jovens \\
\hline & Nomes de pessoas ou cargo/função & deputado, especialista \\
\hline & Pronomes pessoais (incluídos os casos de elipse) & eu, nós, ele \\
\hline & Pronomes indefinidos/demonstrativos/interrogativos & todos, ninguém, quem \\
\hline & Nomes de instituições & câmara, senado, escola, \\
\hline & Objetos semióticos & estudos, lei, notícia, história \\
\hline & Abstrações semióticas & $\begin{array}{l}\text { polêmica, posicionamento, } \\
\text { opinião }\end{array}$ \\
\hline & Objetos materiais & livros, cartaz \\
\hline & Campo/assunto/tema do texto & $\begin{array}{l}\text { Redução da Maioridade } \\
\text { penal, Escola Sem Partido, } \\
\text { Livros Digitais, Reforma } \\
\text { do Ensino Médio }\end{array}$ \\
\hline
\end{tabular}

Fonte: Autores. 
A ocorrência dos processos e dos participantes no Movimento de Contextualização e a relação estabelecida entre esses recursos são explicitadas na Tabela 1 .

Tabela 1. Relação entre processos e participantes no Movimento 1

\begin{tabular}{|l|r|r|r|r|r|r|r|}
\hline & Materiais & Mentais & Relacionais & Verbais & $\begin{array}{l}\text { Comportamen- } \\
\text { tais }\end{array}$ & Existenciais & TOTAL \\
\hline P1 & 10 & 7 & 7 & 5 & 2 & 3 & 34 \\
\hline P2 & 2 & 1 & 1 & 4 & 0 & 0 & 8 \\
\hline P3 & 8 & 1 & 2 & 7 & 1 & 0 & 19 \\
\hline P4 & 5 & 5 & 5 & 3 & 1 & 0 & 19 \\
\hline P5 & 0 & 0 & 1 & 1 & 1 & 0 & 3 \\
\hline P6 & 7 & 0 & 2 & 0 & 0 & 0 & 9 \\
\hline P7 & 13 & 4 & 13 & 1 & 0 & 3 & 34 \\
\hline P8 & 2 & 0 & 0 & 0 & 0 & 0 & 2 \\
\hline P9 & 6 & 0 & 27 & 2 & 0 & 2 & 37 \\
\hline TOTAL & 53 & 18 & 58 & 23 & 5 & 8 & 165 \\
\hline
\end{tabular}

\section{Fonte: Autores.}

No Movimento 1, o participante com maior ocorrência foi campo do texto (Exemplo 5), evidenciando que os alunos destacam o assunto do texto e buscam conceituá-lo utilizando processos relacionais.

Exemplo 5.- Campo do texto

\begin{tabular}{|l|l|l|}
\hline [A reforma do ensino médio] & tem & seu lado bom e seu lado ruim \\
\hline Portador & Processo relacional & Atributo \\
\hline
\end{tabular}

Art\#.2.17.REM.

Além disso, os participantes nome genérico (Exemplo 6) e abstração semiótica (Exemplo 7) foram combinados, em maior número, com processos materiais que indicam situações reais ou hipotéticas no Passo 1c, que é utilizado para apresentação de fatos, conforme os exemplos.

Exemplo 6 - Nome genérico

\begin{tabular}{|l|l|l|}
\hline [o jovem] & não pode cometer & crimes \\
\hline Ator & Processo material & Meta \\
\hline
\end{tabular}

Art\#.2.15.RMP. 
Exemplo 7 - Abstração semiótica

\begin{tabular}{|l|l|l|}
\hline [um debate] & ocorre & de norte a sul do país \\
\hline Ator & Processo material & Circunstância \\
\hline
\end{tabular}

Art\#.2.16.RMP.

O emprego dos participantes exemplificados acima evidencia que os recursos linguísticos considerados significativos pelos alunos são aqueles relacionados, primeiramente, com a construção do campo do texto. Após demarcar o assunto de que trata o artigo, os alunos recorrem a recursos que personificam um agente (o jovem) e que apontam a construção de um conhecimento generalizado (um debate). Nesse sentido, Barton (2002) defende que escritores inexperientes utilizam construções linguísticas que indicam que o conhecimento é geral/generalizado, produto de uma concordância compartilhada pelos membros da sociedade sem a necessidade de comprovação ou prova empírica, o que nos parece evidente nos exemplos de 5 a 7 .

Em relação aos recursos interpessoais utilizados no Movimento 1, os mais utilizados são as negações, que somam 20 ocorrências, e o modal poder, com 9 ocorrências. O modal poder foi utilizado como indicador de probabilidade - modalidade epistêmica, indicando que produtores inexperientes, em alguns momentos, recorrem à diminuição do grau de certeza empregado na contextualização. Além desses casos, um recurso interpessoal utilizado com certa recorrência no Movimento 1 é a frase interrogativa endereçada ao leitor como estratégia de aproximação e interação, conforme demonstra o Exemplo 8.

\section{Exemplo 8}

A maioridade penal é um debate que ocorre de norte a sul do país, para a mudança ou não da lei, da constituição. É claro que um jovem de 16 anos tem a consciência de que não pode cometer crimes, ele tem consciência para votar, não é mesmo? \#Art2.15.RMP

Por fim, percebemos que a recorrência do participante campo do texto demonstra que os alunos realizam um esforço para situarem o leitor acerca do tema polêmico. Esse participante é associado a processos relacionais nos quais há uma tentativa de apresentação do tema. Aqui nos deparamos com um aspecto problemático, pois a maior ocorrência do Passo $1 \mathrm{~d}$ - Generalização sobre o campo, demonstra que essa tentativa não é eficaz, pois diminui a força argumentativa. Esse passo associado à utilização de participantes nomes genéricos e abstrações semióticas, além da utilização de negações, que são uma forma de rejeitar vozes externas, demonstra que os alunos, produtores pouco experientes, generalizam o campo, não demarcando 
claramente o contexto/tema polêmico apresentado ao leitor. A seguir uma síntese das características linguísticas empregadas no Movimento 1.

Quadro 6. Marcas linguísticas do Movimento 1

\begin{tabular}{|l|l|l|l|}
\hline Movimentos & Processos & Participantes & $\begin{array}{l}\text { Recursos } \\
\text { interpessoais }\end{array}$ \\
\hline \multirow{4}{*}{ 1. Contextualização } & Materiais: 53 & $\begin{array}{l}\text { P1 nomes genéricos: 34 } \\
\text { P7 abstrações }\end{array}$ & $\begin{array}{l}\text { Verbos modais: poder } \\
\text { 9xi dever 4x; adjuntos } \\
\text { modais: não 20x; }\end{array}$ \\
& Relacionais: 58 & $\begin{array}{l}\text { semióticas: } 34 \\
\text { P9 campo/assunto de } \\
\text { texto: 37 }\end{array}$ & $\begin{array}{l}\text { outros recursos: frases } \\
\text { interrogativas 6x. }\end{array}$ \\
\hline
\end{tabular}

Fonte: Autores

\subsection{Movimento 2 - Apresentação da Tese}

No Movimento 2 - Apresentação da tese, é encontrado um elemento central do artigo de opinião: o posicionamento do aluno-autor. Essa posição, supostamente, deve estar clara para o leitor, já que a sua explicitação orientará sua argumentação. Por meio da análise, verificamos que a grande maioria dos textos (52) apresenta um posicionamento explícito sobre o tema debatido.

\section{Exemplo 9 - Passo 2a}

Os professores deveriam apresentar e expressar suas opiniões para o aluno, para que o aluno entenda todos os lados das opiniões, mas o professor deve apresentar e expressar com respeito à política, ideologia e religião do aluno. \#Art.9.16.ESP.

\section{Exemplo 10 - Passo 2a}

Eu sou a favor da maioridade penal porque eu acho que os jovens já têm consciência dos seus próprios atos, e se cometerem crimes devem pagar por isso e assim deve diminuir a criminalidade das ruas. \#Art.1.15.RMP.

Em relação aos significados ideacionais presentes no Movimento de Apresentação da tese, foram identificadas 170 orações, com a ocorrência dos processos e participantes explicitada na Tabela 2. 
Tabela 2. Relação entre processos e participantes no Movimento 2

\begin{tabular}{|l|r|r|r|r|r|r|r|}
\hline & Materiais & Mentais & Relacionais & Verbais & $\begin{array}{l}\text { Comporta- } \\
\text { mentais }\end{array}$ & Existenciais & TOTAL \\
\hline P1 & 29 & 10 & 15 & 3 & 0 & 1 & 58 \\
\hline P2 & 0 & 0 & 0 & 3 & 0 & 0 & 3 \\
\hline P3 & 10 & 8 & 25 & 12 & 2 & 0 & 57 \\
\hline P4 & 4 & 3 & 4 & 0 & 0 & 1 & 12 \\
\hline P5 & 4 & 1 & 2 & 0 & 1 & 0 & 8 \\
\hline P6 & 3 & 1 & 2 & 1 & 0 & 0 & 7 \\
\hline P7 & 1 & 1 & 4 & 1 & 0 & 4 & 11 \\
\hline P8 & 1 & 0 & 0 & 0 & 0 & 0 & 1 \\
\hline P9 & 6 & 0 & 7 & 0 & 0 & 0 & 13 \\
\hline TOTAL & 58 & 24 & 59 & 20 & 3 & 6 & 170 \\
\hline
\end{tabular}

Fonte: Autores.

Há semelhança entre os números de processos e participantes nos Movimentos 1 e 2. A diferença significativa surge em relação ao uso recorrente do participante pronome pessoal. Os pronomes pessoais utilizados no Movimento 2 estão vinculados a processos que explicitam o posicionamento do autor. Na maioria dos casos o pronome pessoal "eu" vincula-se a um processo mental (Exemplo 11) ou a um processo relacional seguido de expressões como "a favor" ou "contra" (Exemplo 12).

Exemplo 11 - Pronome pessoal

\begin{tabular}{|l|l|l|}
\hline Eu & acredito, & sim, que a maioridade penal \\
\hline Experienciador & Processo mental & Fenômeno \\
\hline
\end{tabular}

\#Art.5.15.RMP

Exemplo 12 - Pronome pessoal

\begin{tabular}{|l|l|l|}
\hline Eu & sou & a favor da maioridade penal \\
\hline Identificado & Processo relacional & Identificador \\
\hline
\end{tabular}

\#Art.1.15.RMP

Em relação aos recursos interpessoais utilizados no Movimento 2, as negações somam 27 ocorrências (Exemplo 15). Identificamos também a ocorrência de adjuntos modais de tipicalidade e usualidade com 5 ocorrências (Exemplo 16) e verbos modais de probabilidade (modalidade epistêmica) e obrigação (modalidade deôntica), conforme os Exemplos 17 e 18. 


\section{Exemplo 15}

Mas não se trata apenas em proibir os professores de expressar sua opinião, mas também de tirar o pensamento crítico do aluno, a não capacitação de lidar com o mundo cruel em que vivemos, onde ele só viveria no 'mundinho' dele e não haveria contradições para lhe trazer a realidade. As contradições devem aparecer para formar cidadãos mais tolerantes. \# Art.10.16. ESP

\section{Exemplo 16}

A redução da maioridade penal não é a melhor escolha a ser feita. Enquanto o nosso governo investir mais em entretenimento do que em educação, nunca será possível a redução de menores infratores. \#Art.14.16.RMP

\section{Exemplo 17}

Não se pode deixar alguém que comete crime impune. \#Art.16.16.RMP

\section{Exemplo 18}

Não deveria existir isso, porque se o jovem, mata, ele tem consciência do que fez, ninguém mata por acaso o sem querer. Isso é meio que inacreditável, não prender menor de 18 que matou, se matou ou cometeu qualquer crime deve responder como menor de idade. \#Art.7.15.RMP

As marcas de pessoalidade evidenciam a construção de autoria, por meio de índices linguísticos que explicitam a posição enunciativa assumida. Ainda que, de certa forma, distantes da prática social que envolve o gênero, os alunos-autores buscam empregar recursos que demarquem linguisticamente sua posição como: "eu" e "na minha opinião". O Quadro 7 sintetiza os dados relevantes observados no Movimento 2.

Quadro 7. Marcas linguísticas do Movimento 2

\begin{tabular}{|l|l|l|l|}
\hline Movimento & Processos & Participantes & Recursos interpessoais \\
\hline $\begin{array}{l}\text { 2. Apresentação } \\
\text { da Tese }\end{array}$ & Materiais: 58 & P1 nomes genéricos/pessoas: 58 & Verbos modais: dever 17x; \\
\hline
\end{tabular}

Fonte: Autores

\subsection{Movimento 3 - Defesa da tese}

O Movimento 3 apresenta os argumentos que sustentam as teses dos alunos. $\mathrm{O}$ número de argumentos atua como reforço para a tese defendida e demonstra um maior nível de complexidade na argumentação do aluno (DOLZ, 1996, p. 231). 
Por meio da análise quantitativa, verificamos que 55 textos (93\%) apresentam um argumento para defesa da tese, 40 textos (68\%) apresentam minimamente dois argumentos para defesa da tese, enquanto 12 textos (20\%) apresentam três. A utilização de somente um ou dois argumentos caracteriza a escrita desses estudantes, conforme apresentamos a seguir.

Exemplo 19 - Passos 3a e 3b

3a. Pense bem, se o professor não traz um assunto para debate em sala de aula o aluno talvez nem saiba dele e você não deixa o aluno tirar suas próprias conclusões sobre o que é certo ou errado ela vai se tornar um cidadão sem opinião, sem nexo, sem serventia. Os professores(as) sempre tentam trazer um método novo de ensinar e tornar a aula mais atrativa para o aluno, a "Escola sem Partido" ela acaba individualizando as aulas e a tornado menos atraente para o aluno que não vai querer mais assistir as aulas.

3b. "Além de não assumir sua mensagem conservadora, camuflada em suposto pluralismo, o Escola Sem Partido quer evitar um pensamento crítico. Quer uma escola medíocre. Afirma uma ideologia pautada em um fundamentalismo cristão evitado até pelo Papa Francisco, diante das possibilidades de um papado que sucedeu o ultraconservador Bento XVI", afirma Daniel Cara, coordenador-geral da Campanha Nacional pelo Direito à Educação. \#Art.4.16.ESP.

Exemplo 20 - Passo 3a

3a. [...] o aluno vai poder escolher algumas matérias que tem mais interesse, demonstrando assim mais interesse pelas aulas e por ter um número menor de disciplinas que ele tem mais dificuldade, sem falar também no ensino técnico que é uma ótima ajuda para facilitar a entrada no mercado de trabalho, após ou durante o ensino médio. \#Art.3.17.REM.

Os significados ideacionais no Movimento 3 são representados pela utilização dos processos e participantes explicitados na Tabela 3 .

Tabela 3. Relação entre processos e participantes no Movimento 3

\begin{tabular}{|l|r|r|r|r|r|r|r|}
\hline & Materiais & Mentais & Relacionais & Verbais & Comportamentais & Existenciais & TOTAL \\
\hline P1 & 71 & 44 & 14 & 19 & 7 & 4 & 159 \\
\hline P2 & 5 & 3 & 1 & 16 & 5 & 0 & 30 \\
\hline P3 & 21 & 23 & 9 & 18 & 8 & 0 & 79 \\
\hline P4 & 13 & 9 & 8 & 3 & 1 & 0 & 34 \\
\hline P5 & 20 & 3 & 3 & 3 & 0 & 1 & 30 \\
\hline P6 & 14 & 1 & 11 & 5 & 0 & 2 & 33 \\
\hline P7 & 8 & 1 & 11 & 6 & 0 & 1 & 27 \\
\hline
\end{tabular}




\begin{tabular}{|l|r|r|r|r|r|r|r|}
\hline P8 & 3 & 0 & 2 & 0 & 0 & 0 & 5 \\
\hline P9 & 3 & 2 & 1 & 1 & 2 & 0 & 9 \\
\hline $\begin{array}{l}\text { TO- } \\
\text { TAL }\end{array}$ & 158 & 86 & 60 & 71 & 23 & 8 & 406 \\
\hline
\end{tabular}

Fonte: Autores

No Movimento 3 identificamos 406 orações. Nessas orações a maior ocorrência é de processos materiais, mentais e verbais. Os participantes nomes genéricos e pronomes pessoais são empregados com maior frequência pelos autores, conforme demonstramos a seguir.

Exemplo 21 - Nome genérico

\begin{tabular}{|l|l|l|}
\hline Um jovem de 16 anos & mata & uma pessoa com uma arma \\
\hline Ator & Processo material & Meta \\
\hline
\end{tabular}

\#Art.10. 15.RMP

Os processos mentais apresentam a segunda maior ocorrência no Movimento 3. Nas orações que apresentam esses processos, os alunos utilizam um experienciador coletivo, um pronome ou um nome genérico, que tem percepções sobre a problemática do texto.

Exemplo 22 - Nome genérico

\begin{tabular}{|l|l|l|}
\hline Os jovens & pensam & que podem fazer o que entendem \\
\hline Experienciador & Processo mental & Fenômeno \\
\hline
\end{tabular}

\#Art.8.15.RMP

Essas construções textuais, destacadas acima, criam cenários em que há posicionamentos expressos por participantes pronomes associados a processos relacionais ou a processos materiais. Em ambos os casos esses posicionamentos decorrem da existência de uma atividade desenvolvida por um participante nome genérico. Para exemplificar essa situação, teríamos a seguinte proposição: "os jovens matam, por isso defendo a maioridade penal". Esses elementos, além da larga utilização de negações, geralmente associadas ao modal dever - modalidade deôntica -, novamente criam um espaço de fechamento do diálogo, no qual o aluno assume sua posição de forma assertiva.

Os participantes nomes de pessoas ou cargo função aparecem combinados a processos verbais. Essa construção linguística é típica de argumentos de autoridade, 
argumentos esses que são utilizados de modo a possibilitar uma maior confiabilidade da posição defendida pelo aluno-autor.

Exemplo 23 - Nomes de pessoas ou cargo/função

\begin{tabular}{|l|l|l|}
\hline O advogado Miguel Nagib & afirma & que o Escola Sem Partido \\
\hline Dizente & Processo verbal & Verbiagem \\
\hline
\end{tabular}

\#Art.2.16.ESP

Os recursos interpessoais mais comuns, novamente, são adjuntos de negação (96 ocorrências) e verbos modais, especialmente o modal poder - modalidade epistêmica (36 ocorrências). O modal dever - modalidade deôntica - também aparece (18 ocorrências) para atuar como reforço da tese e já antecipar ações que poderiam ser tomadas. As frases interrogativas são também utilizadas com o objetivo de instigar o leitor e reforçar a posição assumida (13 ocorrências).

\section{Exemplo 24}

[...] a escola não poderá ensinar a Declaração dos Direitos do Homem? A extrema direita o que quer?. \#Art.14.16.ESP

As características representativas do Movimento 3 são apresentadas no Quadro 8.

Quadro 8. Marcas linguísticas do Movimento 3

\begin{tabular}{|c|c|c|c|}
\hline Movimento & Processos & Participantes & Recursos interpessoais \\
\hline $\begin{array}{l}\text { 3. Defesa } \\
\text { da tese }\end{array}$ & $\begin{array}{l}\text { Materiais: } 158 \\
\text { Mentais: } 86 \\
\text { Verbais: } 71\end{array}$ & $\begin{array}{l}\text { P1 nomes genéricos/pessoas: } 159 \\
\text { P3 pronomes pessoais: } 79 \\
\text { P4 pronomes indefinidos: } 34\end{array}$ & $\begin{array}{l}\text { Verbos modais: dever } 18 x_{i} \\
\text { poder } 36 x \text {. } \\
\text { Adjuntos modais: ainda } 5 x_{;} \text {não } \\
96 x_{;} \text {nem } 8 x_{;} \\
\text {Adjuntos de comentário: na mi- } \\
\text { nha opinião } 4 x_{;} \text {realmente } 3 x_{;} \\
\text {Expressões modalizadoras: é } \\
\text { certo } 2 x_{i} \\
\text { Outros recursos: frases interro- } \\
\text { gativas } 13 x_{i}\end{array}$ \\
\hline
\end{tabular}

Fonte: Autores

No Movimento 3, observamos uma maior utilização de processos mentais e verbais em relação aos demais Movimentos, nos quais apenas os processos materiais e relacionais apresentavam números consideráveis. Isso indica que os jovens escritores refletem sobre a problemática, já que utilizam processos mentais 
relacionados a nomes genéricos e a pronomes pessoais. Além disso, a utilização de processos verbais relacionados a nomes de pessoas para construir argumentos de autoridade aponta para conscientização acerca da necessidade de sustentar sua posição com base em vozes externas e sinaliza que o jovem estudante começa a demarcar seu espaço autoral e a reconhecer sua voz como parte de um conjunto de vozes e discursos que circulam na sociedade.

\subsection{Movimento 4 - Síntese e reiteração}

No Movimento 4, dentre os passos 4a - Apresentação de medidas ou soluções para o problema debatido - e $4 \mathrm{~b}$-Apresentação de conclusões com base nas premissas dos argumentos - a escolha preferencial dos alunos foi pela apresentação de soluções para o problema debatido (Exemplo 25), o que ocorreu em 34 exemplares.

\section{Exemplo 25 - Passo 4a}

Para que todos tenham direito de expressar sua opinião, também devemos respeitar a opinião de outras pessoas [...]. Sendo assim teremos adultos, jovens, crianças independentes e com olhares críticos para a vida. \#Art.13.16.ESP

O número de exemplares sem o Movimento 4 é relevante: 15 , representando $25 \%$ do total. A ausência desse movimento nos textos pode ser um indicativo do processo de escolarização do gênero e da pouca familiaridade com gênero artigo de opinião, evidenciando a aproximação, em alguma medida, com a redação escolar. Os significados ideacionais do Movimento 4 são quantificados na Tabela 4.

Tabela 4. Relação entre processos e participantes no Movimento 4

\begin{tabular}{|l|r|r|r|r|r|r|r|}
\hline & Materiais & Mentais & Relacionais & Verbais & $\begin{array}{l}\text { Comportamen- } \\
\text { tais }\end{array}$ & Existenciais & TOTAL \\
\hline P1 & 18 & 8 & 6 & 2 & 4 & 2 & 40 \\
\hline P2 & 3 & 1 & 0 & 1 & 1 & 0 & 6 \\
\hline P3 & 12 & 14 & 7 & 9 & 2 & 0 & 44 \\
\hline P4 & 2 & 5 & 5 & 1 & 3 & 0 & 16 \\
\hline P5 & 4 & 1 & 0 & 1 & 0 & 1 & 7 \\
\hline P6 & 5 & 0 & 4 & 0 & 0 & 0 & 9 \\
\hline P7 & 2 & 0 & 6 & 0 & 1 & 3 & 12 \\
\hline P8 & 0 & 0 & 1 & 0 & 0 & 0 & 1 \\
\hline P9 & 6 & 1 & 4 & 1 & 0 & 0 & 12 \\
\hline TOTAL & 52 & 30 & 33 & 15 & 11 & 6 & 147 \\
\hline
\end{tabular}

Fonte: Autores 
Foram identificadas 147 orações no Movimento 4. Há predominância de processos materiais, relacionais e mentais. Os participantes mais frequentes são pronomes pessoais e nomes genéricos, conforme os exemplos.

Exemplo 26 - Nome genérico

\begin{tabular}{|l|l|l|}
\hline jovens & cometem & crimes \\
\hline Ator & Processo material & Meta \\
\hline
\end{tabular}

\#Art.6.15.RMP

A utilização de pronomes pessoais, especialmente do pronome de primeira pessoa do plural, indica uma aproximação com o leitor, a fim de convencê-lo da validade das medidas e da necessidade do trabalho conjunto para que as medidas sejam implementadas. Vejamos os exemplos.

Exemplo 27 - Pronome pessoal

\begin{tabular}{|l|l|l|}
\hline [nós] & vamos mudar & [isso] \\
\hline Ator & Processo material & Meta \\
\hline
\end{tabular}

\#Art.3. 15.RMP

Como parte da indicação de medidas a serem tomadas, são utilizadas expressões modalizadoras de obrigação, como "é necessário", e verbos modais que indicam obrigação (modalidade deôntica), conforme o exemplo a seguir.

Exemplo 28

Mas isso é uma questão política, que talvez demore um pouco para ser resolvida, porém os jovens que cometem crimes não devem ficar impunes em relação aos seus crimes, e é necessário que os mesmos paguem por seus atos. \#3.16.RMP

Somam-se a esses elementos a ocorrência de negações, num total de 25, geralmente associadas a verbos modais (dever, modalidade deôntica, 26 ocorrências) para reforçar o caráter de prescrição das medidas propostas pelo aluno. Isso evidencia que os escritores menos experientes reconhecem a importância de engajar seus leitores para que a tese seja aceita.

Exemplo 29

"A escola deve ser fonte de aprendizado. não pode ser um instrumento para violar o que os pais ensinam em casa". \#Art.6.16.ESP

Por fim, apresentamos uma síntese das características do Movimento 4: 
Quadro 9. Marcas linguísticas do Movimento 4

\begin{tabular}{|c|c|c|c|}
\hline Movimento & Processos & Participantes & Recursos interpessoais \\
\hline $\begin{array}{l}\text { 4. Síntese e } \\
\text { reiteração }\end{array}$ & $\begin{array}{l}\text { Materiais: } 52 \\
\text { Mentais: } 30 \\
\text { Relacionais: } 33\end{array}$ & $\begin{array}{l}\text { P1 nomes genéricos/ } \\
\text { pessoas: } 40 \\
\text { P3: pronomes } \\
\text { pessoais } 44\end{array}$ & $\begin{array}{l}\text { Verbos modais: poder } 8 x_{i} \text { dever } 26 x_{i} \\
\text { Adjuntos modais: } \operatorname{sim} 9 x_{i} \text { não } 25 \mathrm{x} \\
\text { Expressões modalizadoras: na minha } \\
\text { opinião } 4 x_{i} \text { é necessário } 3 x_{i} \\
\text { Outros recursos: frases interrogativas } 3 x \text {. }\end{array}$ \\
\hline
\end{tabular}

Fonte: Autores.

Dentre os recursos linguísticos analisados, além daqueles já destacados em Movimentos anteriores, observamos a utilização do participante pronome pessoal "nós" relacionado a processos materiais como uma tentativa de engajar o leitor nas medidas apresentadas pelo autor. Porém, novamente, o excesso de negações mantém o espaço fechado para o debate, ou seja, para o aluno, parece não haver negociação, já que a única posição válida é a do autor.

Os dados obtidos no Movimento 4 reforçam o caráter iniciante da escrita dos alunos, já que 15 textos não apresentam esse movimento. Dentre aqueles que apresentam o movimento final, destacamos, em relação à escolha da estratégia utilizada, o fato de que a proximidade existente entre o artigo de opinião e a redação escolar ou redação do ENEM pode ter influenciado a escolha pelo Passo 4a - Apresentação de medidas ou soluções para o problema debatido, com 34 ocorrências - tal como é solicitado no Exame. Já a existência do Passo 4b Apresentação de conclusões com base nas premissas dos argumentos, sugere um esforço argumentativo por parte dos alunos no sentido de apresentar considerações finais em seus artigos.

\section{CONSIDERAÇÕES FINAIS}

Neste trabalho buscamos analisar as características linguístico-discursivas recorrentes em artigos de opinião produzidos por estudantes da educação básica, especificamente do $9^{\circ}$ ano do Ensino Fundamental. Em termos de organização retórica, verificamos que os artigos de opinião escritos pelos alunos apresentam os seguintes Movimentos: 1 - Contextualização; 2 - Apresentação da tese $e_{i} 3$ Defesa da tese; 4 - Síntese e reiteração. Quantificando os dados, constatamos que os alunos utilizam com maior frequência os Movimentos 2 e 3.

A maior utilização dos Movimentos 2 e 3, os quais explicitam o posicionamento do autor e os argumentos que sustentam esse posicionamento, sugere que os alunos possuem certa familiaridade com a produção de textos argumentativos. A 
dificuldade observada na escrita dos Movimentos 1 e 4 deve-se, acreditamos, às especificidades do gênero artigo de opinião, já que esses movimentos podem ser compreendidos como os elementos que diferenciam o artigo de opinião de gêneros familiares como a redação escolar.

Em relação à análise dos elementos léxico-gramaticais, no Movimento 1, a utilização do Passo 1d - Generalização sobre o campo, associado à utilização de participantes nomes genéricos, abstrações semióticas, além de negações, que são uma forma de rejeitar vozes externas, demonstra que alunos escritores inexperientes tendem a generalizar o campo e a fechar seu discurso. No Movimento 2, observamos maior incidência de processos materiais, relacionais e verbais juntamente com a utilização de participantes que indicam o posicionamento do autor, por exemplo, os pronomes pessoais. Esses elementos, aliados à utilização de negações, por vezes associadas ao modal dever, criam um espaço de fechamento do diálogo, no qual o aluno assume sua posição de forma assertiva, com um esforço argumentativo para consolidar sua posição e demarcar sua autoria.

No Movimento 3, constatamos o emprego frequente de processos mentais e verbais, evidenciando: i) a indicação de reflexões sobre a problemática, por parte do aluno autor, ao utilizar processos mentais relacionados a nomes genéricos e a pronomes pessoais; ii) a utilização processos verbais relacionados a argumentos de

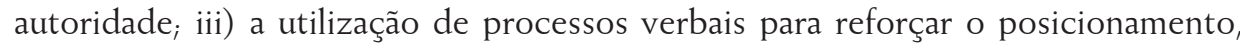
associados a participantes pronomes pessoais, tal como ocorreu no Movimento 2. Por último, dentre os recursos lexicais observados no Movimento 4, além daqueles já destacados em movimentos anteriores, observamos a utilização do participante pronome pessoal "nós" relacionado a processos materiais como uma tentativa de engajar o leitor nas medidas apresentadas pelo autor.

As produções, portanto, constituem um interessante mapa para a proposição de práticas de escrita situadas, já que fornecem pistas do processo de apropriação do gênero artigo de opinião e de como se constrói a autoria em contexto escolar. Dessa forma, entendemos que esses achados podem fomentar a produção de materiais didáticos que privilegiem atividades e tarefas didáticas que auxiliem os jovens escritores em sua prática discursiva de maneira explícita. Em nosso contexto de atuação, os achados foram recontextualizados em um caderno didático intitulado "Produzindo artigo de opinião" (BORDIM; PINTON, SCHMITT, 2019), que circula em escolas vinculadas ao Programa Residência Pedagógica, do munícipio de Santa Maria (RS). 


\section{REFERÊNCIAS}

BAKHTIN, M. (2011). Gêneros do Discurso. In: Estética da Criação Verbal, trad. Paulo Bezerra. 6. ed. São Paulo: Martins Fontes, pp. 261-306.

BARROS, J. B. S. (2016). A produção de artigos de opinião por alunos do Ensino Fundamental: A construção da contra-argumentação mediada por operadores de conformidade e contraposição. Dissertação de Mestrado Profissional em Letras. Universidade Federal da Paraíba, Mamanguape$\mathrm{PB}$.

BARTON, E. (2004). Linguistic Discourse Analysis: How the Language in Texts Works. In: What writing does and how it does it: an introduction to analyzing texts and textual practices. Ed. Charles Bazerman. Mahwah N.J.: Lawrence Erlbaum Associates.

BAZERMAN, C. (2011a). Gêneros textuais, tipificação e interação. Judith C. Hoffnagel; Ângela P. Dionísio (orgs)São Paulo: Cortez.

BAZERMAN, C. (2011b). Gênero, Agência e Escrita. Judith C. Hoffnagel; Ângela P. Dionísio (orgs). São Paulo: Cortez.

BAZERMAN, C. (2015). Retórica da Ação Letrada, trad. Adail Sobral, Angela Dionisio, Judith Chambliss Hoffnagel, Pietra Acunha. 1.ed. São Paulo: Parábola Editorial.

BORDIM, C. T.; PINTON, F. M.; SCHMITT, R. M. (org.). (2019). Produzindo artigo de opinião. 3. ed. Santa Maria, RS: UFSM, CAL, Curso de Letras.

BRÄKLING, K. L. (2000). Trabalhando com artigo de opinião: re-visitando o eu no exercício da (re)significação da palavra do outro. In: ROJO, R. (org.) A prática da linguagem em sala de aula: praticando os PCN's. São Paulo: EDUC; Campinas: Mercado de Letras.

CUNHA, M. A. F. da; SOUZA, M. M. (2011). Transitividade e seus contextos de uso. São Paulo: Cortez.

DOLZ, J. (1996). Learning Argumentative Capacities A Study of the Effects of a Systematic and Intensive Teaching of Argumentative Discourse in 11-12 Year Old Children. Argumentation - Kluwer Academic Publishers. Printed in the Netherlands, n. 10, p. 227-251.

FERREIRA, M. S. (2018). Estratégias argumentativas na produção escrita de artigo de opinião no Ensino Fundamental. Dissertação de Mestrado Profissional em Letras. Universidade Federal do Ceará. Fortaleza. 
FREITAS, E. S. (2009). O gênero artigo de opinião do programa escrevendo o futuro: estudo de caso. Dissertação de Mestrado em Ciências da Linguagem. Universidade do Sul de Santa Catarina - Unisul. Tubarão-SC.

FUZER, C.; CABRAL, S.R.S. (2014). Introdução à Gramática Sistêmico-Funcional em Língua Portuguesa. Campinas, SP: Mercado de Letras.

GAGliARDI, E; AMARAL, H. (2004). Pontos de vista. São Paulo: Peirópolis.

HALLIDAY, M. A. K.; MATTHIESSEN, C. M. I. M. (2014). Halliday's Introduction to Functional Grammar. New York / London: Routledge.

MILLER, C. (1994). Genre as Social Action. In: FREEDMAN, A.; MEDWAY, P. (eds). Genre and the New Rethoric. London. Taylor and Francis, London, UK, pp. 23-42.

MISES, L. V. (2010). Ação Humana, trad. Donald Stewart Jr. São Paulo: Instituto Ludwig von Mises Brasil.

OLIVEIRA, C. M. M. (2004). A organização retórica de artigos de opinião na imprensa e no jornal escolar. Dissertação de Mestrado em Linguística, Curso de Pós-Graduação em Estudos Linguísticos da Universidade Federal do Ceará, Fortaleza, Ceará.

PERELMAN, C.; OLBRECHTS-TYTECA, L. (2014). Tratado da argumentação: A Nova Retórica, trad. Maria Ermantina de Almeida Prado Galvão. 3. ed. São Paulo: Martins Fontes.

RIBEIRO, J. A. (2012). sequência argumentativa e as categorias de argumentos no texto escolar nos níveis de ensino fundamental e médio. Tese de Doutorado em Linguística, Curso de Pós-Graduação em Estudos Linguísticos da Universidade Federal do Paraná, Curitiba.

SANTOS, R. M. B. (2015). Argumentação: uma análise da organização textual em produções escritas de ensino médio. Tese de Doutorado em Letras, Curso de Pós-Graduação em Letras da Universidade Federal do Paraná, Curitiba.

SWALES, J. M. (1990). Genre Analysis: English in academic and research settings. New York: Cambridge University Press.

Recebido: 30/06/2019

Aceito: 4/10/2019

Publicado: 9/10/2019 